\title{
BMJ Open Reactions and coping strategies in lay rescuers who have provided CPR to out-of-hospital cardiac arrest victims: a qualitative study
}

\author{
Wenche Torunn Mathiesen, ${ }^{1,2}$ Conrad Arnfinn Bjørshol, ${ }^{1,3}$ Geir Sverre Braut,, ${ }^{4,5}$ \\ Eldar Søreide ${ }^{1,6}$
}

To cite: Mathiesen WT, Bjørshol CA, Braut GS, et al. Reactions and coping strategies in lay rescuers who have provided CPR to out-ofhospital cardiac arrest victims: a qualitative study. BMJ Open 2016;6:e010671. doi:10.1136/bmjopen-2015010671

- Prepublication history and additional material is available. To view please visit the journal (http://dx.doi.org/ 10.1136/bmjopen-2015010671).

Received 26 November 2015 Revised 1 April 2016 Accepted 6 May 2016

CrossMark

For numbered affiliations see end of article.

Correspondence to Wenche Torunn Mathiesen; wenche.torunn.mathiesen@ sus.no

\section{ABSTRACT}

Objective: Cardiopulmonary resuscitation (CPR) provided by community citizens is of paramount importance for out-of-hospital cardiac arrest (OHCA) victims' survival. Fortunately, CPR rates by community citizens seem to be rising. However, the experience of providing CPR is rarely investigated. The aim of this study was to explore reactions and coping strategies in lay rescuers who have provided CPR to OHCA victims.

Methods, participants: This is a qualitative study of 20 lay rescuers who have provided CPR to 18 OHCA victims. We used a semistructured interview guide focusing on their experiences after providing CPR.

Setting: The study was conducted in the Stavanger region of Norway, an area with very high bystander CPR rates.

Results: Three themes emerged from the interview analysis: concern, uncertainty and coping strategies. Providing CPR had been emotionally challenging for all lay rescuers and, for some, had consequences in terms of family and work life. Several lay rescuers experienced persistent mental recurrences of the OHCA incident and had concerns about the outcome for the cardiac arrest victim. Unknown or fatal outcomes often caused feelings of guilt and were particularly difficult to handle. Several reported the need to be acknowledged for their CPR attempts. Health-educated lay rescuers seemed to be less affected than others. A common coping strategy was confiding in close relations, preferably the health educated. However, some required professional help to cope with the OHCA incident.

Conclusions: Lay rescuers experience emotional and social challenges, and some struggle to cope in life after providing CPR in OHCA incidents. Experiencing a positive patient outcome and being a health-educated lay rescuer seem to mitigate concerns. Common coping strategies are attempts to reduce uncertainty towards patient outcome and own CPR quality. Further studies are needed to determine whether an organised professional follow-up can mitigate the concerns and uncertainty of lay rescuers.

\section{Strengths and limitations of this study}

- This study describes the experiences of lay rescuers who have provided cardiopulmonary resuscitation (CPR) to out-of-hospital cardiac arrest victims, which little previous research has focused on.

- The results presented in this study give an understanding of the unwanted aspects of providing CPR.

- This study may stimulate health authorities to organise follow-up systems to mitigate concerns and uncertainty in lay rescuers.

- In most of the resuscitations initiated by the persons interviewed in this study, the cardiac arrest victims survived. This does not reflect the survival rate in our area and may have biased the results.

\section{INTRODUCTION}

In Europe, $\sim 275000$ persons experience out-of-hospital cardiac arrest (OHCA) annually. ${ }^{1}$ Bystander cardiopulmonary resuscitation (CPR) increases the chances of survival twofold to threefold. ${ }^{2}$ Bystander CPR rates differ substantially worldwide, ranging from $1.5 \%$ to $73 \% .^{3}{ }^{4}$ However, new studies have revealed that bystander CPR rates are rising, both in the UK and on a global scale. ${ }^{5-8}$

Though the main focus and concern in an OHCA incident is for the cardiac arrest patient, the existing data about the reactions of lay rescuers following CPR provision are sparse and divergent. Zijlstra et at found that lay rescuers did not show post-traumatic stress-disorder-related symptoms 4-6 weeks after performing bystander CPR, while Genest $e t a l^{10}$ reported that unsuccessful CPR attempts lead to persistent adverse effects. Møller et $a l^{11}$ found the debriefing of bystanders to be beneficial and found good coping 
strategies and no severe psychological sequelae in the studied lay rescuers who had provided CPR during an OHCA. However, in the first two studies, the lay rescuers took part in a volunteer first responder system. Hence, they were probably prepared for and interested in responding to an OHCA incident. In the study by Møller et al, only about half of the bystanders had actually performed CPR, which, in addition to being debriefed shortly after the OHCA, may partly explain the positive results.

The few studies concerning lay rescuers' experiences and reactions following CPR provision show that the OHCA victim ultimately dying and a lack of debriefing influence lay rescuers in a negative way. ${ }^{12} 13$

Given this background, we wanted to explore the reactions and coping strategies of lay rescuers following the provision of CPR to OHCA victims.

\section{METHODS}

In this study, we chose a qualitative research method which is suitable for explorative studies. ${ }^{14}$ Lay rescuer was defined as an individual having provided CPR with no professional obligations in the incident. We designed and used an in-depth, open-ended, semistructured interview guide (see online supplementary material for the interview guide), with the aim of exploring the lay rescuers' own experiences and avoiding imposing our assumptions as far as possible. The original interview guide was followed through the entire study. In addition, we increasingly emphasised the elaborated subjects by the lay rescuers in the following interviews. The study was conducted from September 2013 to October 2014.

\section{Setting}

We conducted this study in Norway, primarily with lay rescuers from the Stavanger region, an area that has been identified as having a high bystander CPR rate. ${ }^{4}$ The organisation of the Norwegian emergency medical service (EMS) response to OHCA incidents has been described previously. ${ }^{4}$ To the best of our knowledge, there is no organised follow-up system in Norway offered to lay rescuers after having provided CPR. Confidentiality regarding hospitalised or EMS-treated individuals is secured by explicit norms in Norwegian health legislation; thus, information about them is not readily available to the general public.

\section{Data collection and sampling}

The inclusion criteria were lay rescuers aged 18 years and above, being able to communicate in a Scandinavian language or the English language and having provided CPR with no professional obligations to a non-traumatic adult OHCA victim. We planned this study using a convenience sampling strategy, which means involving accessible subjects. ${ }^{15}$ As one of the inclusion methods, the ambulance personnel distributed 50 flyers about the study to lay rescuers in OHCA settings. Only one lay rescuer contacted us. This unsuccessful way of inclusion led to alternative ways of including participants. Thus, we added a purposive snowball sampling strategy (study features in the local newspaper and proposed candidates who were recommended by individuals in the researchers' network), meaning that the researchers themselves assessed who would provide the best perspective on the phenomenon of interest. ${ }^{16}$ We withdrew two bystanders who did not fulfil the inclusion criteria (did not provide CPR and provided CPR to a child). To reduce the dominating population of lay rescuers in OHCA incidents with positive outcomes, we declined interviews with three lay rescuers where this was the case.

We included 20 lay rescuers from 18 OHCA incidents, primarily from the Stavanger region. The lay rescuers were either 'related' (family or spouse), 'known' (colleagues or acquaintances) or 'unknown' (complete stranger) (table 1). They had all performed chest compressions and/or mouth-to-mouth ventilation. Five informants were health educated (three nurses, one paramedic, one nursing assistant), but without any professional or organised voluntary obligations in the OHCA incident. The time span from CPR training to the OHCA incident ranged from 1 week to 36 years. One lay rescuer had no prior CPR training. None of the lay rescuers had been offered any kind of formal follow-up, except for two who were contacted by EMS personnel shortly after the OHCA incident in what seems to have been ad hoc initiatives. With one exception, the outcome for the OHCA victims (12 survivors, three died in the hospital and two died at the scene) was known to all lay rescuers at the time of the interview. The time from experiencing the OHCA incident to participating in the interview ranged from 6 days to 13 years (median 5.5 years) (table 1). The interviews lasted from 21 to $107 \mathrm{~min}$ (median $40 \mathrm{~min}$ ). Eighteen interviews were conducted in person, and two were conducted by telephone. All interviews were conducted by two interviewers (WTM and $\mathrm{CAB}$ ) introduced as an intensive care nurse and physician, respectively. We collected data regarding lay rescuers' times from OHCA to interview, times from CPR training to OHCA, whether they were health educated or not and their relationship with the OCHA victim. Also, information about the cardiac arrest victims' approximate ages and outcomes was registered. The questions in the interview guide were designed to explore reactions and coping strategies following CPR provision. We encouraged the lay rescuers to discuss their feelings about CPR provision through the interview. Questions raised by the lay rescuers were answered in a discussion following the interviews.

\section{Data analysis}

We used a qualitative, inductive content analysis ${ }^{17}$ to facilitate a deeper understanding of the lay rescuers' experiences of the OHCA. All interviews were audio recorded and transcribed verbatim. To capture the overall meaning, each interview was read through 
Table 1 Characteristics of OHCA victims, outcome and times from OHCA to interview

\begin{tabular}{lllll}
\hline $\begin{array}{l}\text { Participant } \\
\text { number }\end{array}$ & $\begin{array}{l}\text { Approximate. age } \\
\text { of OHCA victim }\end{array}$ & $\begin{array}{l}\text { Relation between lay } \\
\text { rescuer and OHCA victim }\end{array}$ & $\begin{array}{l}\text { OHCA victim } \\
\text { outcome }\end{array}$ & $\begin{array}{l}\text { Time range from OHCA } \\
\text { to interview in years }\end{array}$ \\
\hline 1 & 50 & Unknown & Survived & 0.04 \\
2 & 80 & Known & Died & 0.19 \\
3 & 50 & Unknown & Survived & 0.25 \\
4 & 60 & Unknown & Survived & 6 \\
5 & 50 & Unknown & Survived & 12 \\
6 & 60 & Unknown & Unknown & 1.5 \\
7 & 75 & Unknown & Survived & 7 \\
8 & 65 & Related & Survived & 9 \\
9 & 80 & Unknown & Survived & 9 \\
10 & 45 & Related & Survived & 0.08 \\
11 & 55 & Known & Survived & 1 \\
12 & 55 & Known & Survived & 1 \\
13 & 70 & Known & Survived & 8 \\
14 & 35 & Known & Survived & 0.01 \\
15 & 55 & Known & Survived & 5 \\
16 & 30 & Unknown & Died & 8 \\
17 & 70 & Unknown & Survived & 4 \\
18 & 75 & Unknown & Died & 13 \\
19 & 45 & Known & Died & 12 \\
20 & 50 & Known & Died & 9 \\
\hline OHCA, out-of-hospital cardiac arrest. & & & \\
\hline
\end{tabular}

several times. While endeavouring to stay close to the text, one investigator (WTM) extracted meaning units which were condensed and developed into codes. A meaning unit is considered as words, sentences or paragraphs containing aspects related to each other through their content and context. ${ }^{17}$ An additional investigator $(\mathrm{CAB})$ examined the collection of the statements and performed independent extractions of the same transcribed text.

During the interviews, the lay rescuers repeatedly turned their answers towards how they experienced life after the OHCA incident more than the actual incident. We interpreted the codes regarding this to be the predominant findings and chose these for further analysis. The codes were sorted into subcategories. Finally, based on the subcategories with similar content, we developed three categories: concern, uncertainty and coping strategies and one overarching theme (table 2). During the analysis process, two of the authors (WTM and CB) discussed their choices until a consensus was reached. The text was organised using Nvivo V.10 (QSR International, Victoria, Australia). The results have been reported in accordance with the consolidated criteria for reporting qualitative research checklist. ${ }^{18}$

\section{RESULTS}

All the participants described the OHCA incident as having influenced their lives, though some were affected more than others. The overarching theme, emotional and social challenges and the struggle to cope in life after providing CPR, describes the main findings in this study and also illuminates the complexity in reactions after providing CPR. Table 2 includes examples of the codes used to define subcategories and categories in the analytic process.

\section{Concern}

The first subcategory describes the bodily and emotional influence of the lay rescuers after providing CPR. Several reported the OHCA incident as a shocking and terrifying experience. Nightmares, flashbacks, recurrent and intrusive images of the cardiac arrest victim persisted. Tiredness, exhaustion, confusion, being emotional, being easily distracted and feeling alone about the OHCA experience were individual reactions which could vary in time from days to months. Unwanted weight reduction, anxiety, insomnia and temporary sick leave were experienced following the OHCA incident.

Participant no. 3: I didn't sleep. I kept having nightmares, dreamt the same situation with different outcomes, and then, I went through the same dream with family and friends, and it was just tiring. I wasn't sleeping at all.

Participant no. 6: I lost weight. I found it difficult to eat. Many things changed because of this.

Overall, the lay rescuers reported repetitive selfcriticism regarding whether they could have carried out anything else to achieve a better outcome for the cardiac arrest victim. Their main concern was whether their actions had led to severe injury, a vegetative state or death. Except for the health educated, most lay rescuers strongly linked the quality of their CPR provision to the outcome. 
Table 2 Overview of the overarching theme, categories, subcategories and codes

\begin{tabular}{|c|c|c|c|c|c|c|c|c|}
\hline \multirow{3}{*}{$\begin{array}{l}\text { Theme } \\
\text { Category } \\
\text { Subcategory }\end{array}$} & \multicolumn{8}{|c|}{ Emotional and social challenges and the struggle to cope in life after providing CPR } \\
\hline & \multicolumn{3}{|l|}{ Concern } & \multicolumn{3}{|l|}{ Uncertainty } & \multicolumn{2}{|l|}{ Coping strategies } \\
\hline & $\begin{array}{l}\text { Bodily and } \\
\text { emotional } \\
\text { influence }\end{array}$ & $\begin{array}{l}\text { Self-criticism or } \\
\text { proudness }\end{array}$ & $\begin{array}{l}\text { Changed family } \\
\text { and social } \\
\text { behaviour }\end{array}$ & $\begin{array}{l}\text { In search of } \\
\text { information } \\
\text { about patient } \\
\text { outcome }\end{array}$ & $\begin{array}{l}\text { Experiencing } \\
\text { unavailable } \\
\text { information } \\
\text { about patient } \\
\text { outcome }\end{array}$ & $\begin{array}{l}\text { Receiving } \\
\text { information about } \\
\text { patient outcome }\end{array}$ & $\begin{array}{l}\text { Processing the } \\
\text { OHCA incident }\end{array}$ & $\begin{array}{l}\text { Wishing follow-up by } \\
\text { healthcare } \\
\text { professionals }\end{array}$ \\
\hline Codes & $\begin{array}{l}\text { Having } \\
\text { nightmares } \\
\text { and poor } \\
\text { sleeping } \\
\text { Experiencing } \\
\text { unwanted } \\
\text { weight loss } \\
\text { Feeling } \\
\text { unfocused and } \\
\text { distracted } \\
\text { Recurring the } \\
\text { cardiac arrest } \\
\text { incident in the } \\
\text { mind } \\
\text { Being anxious } \\
\text { Feeling alone } \\
\text { and deserted }\end{array}$ & $\begin{array}{l}\text { Self-blaming } \\
\text { for having not } \\
\text { provided } \\
\text { sufficient CPR } \\
\text { Worrying } \\
\text { about having } \\
\text { inflicted injury } \\
\text { Feeling proud } \\
\text { and happy for } \\
\text { having } \\
\text { provided CPR }\end{array}$ & $\begin{array}{l}\text { Wanting to } \\
\text { be left alone } \\
\text { Avoiding } \\
\text { unwanted } \\
\text { attention } \\
\text { Frightening } \\
\text { unexpected } \\
\text { harm will } \\
\text { happen to } \\
\text { family } \\
\text { members }\end{array}$ & $\begin{array}{l}\text { Struggling } \\
\text { to acquire } \\
\text { patient } \\
\text { information } \\
\text { Wanting to } \\
\text { see and } \\
\text { talk to the } \\
\text { patient }\end{array}$ & $\begin{array}{l}\text { Being kept in } \\
\text { ignorance } \\
\text { because of } \\
\text { the patient } \\
\text { confidentiality } \\
\text { legislation } \\
\text { Finding it } \\
\text { stressful not } \\
\text { knowing } \\
\text { patient } \\
\text { outcome }\end{array}$ & $\begin{array}{l}\text { Experiencing } \\
\text { great relief when } \\
\text { positive } \\
\text { outcome } \\
\text { Experiencing } \\
\text { sadness when } \\
\text { cardiac arrest } \\
\text { victim died or } \\
\text { survived in an } \\
\text { unfortunate } \\
\text { state }\end{array}$ & $\begin{array}{l}\text { Talking to } \\
\text { everyone who } \\
\text { wanted to listen } \\
\text { Communicate } \\
\text { with } \\
\text { health-educated } \\
\text { individuals in } \\
\text { their social } \\
\text { network } \\
\text { Consulting } \\
\text { healthcare } \\
\text { services } \\
\text { Performing } \\
\text { everyday } \\
\text { activities }\end{array}$ & $\begin{array}{l}\text { Needing a } \\
\text { professional, but } \\
\text { optional approach } \\
\text { from healthcare } \\
\text { professionals to } \\
\text { talk about the } \\
\text { OHCA incident } \\
\text { Missing } \\
\text { reassurance of OK } \\
\text { CPR performance } \\
\text { Wanting } \\
\text { acknowledgement } \\
\text { of the CPR attempt } \\
\text { by health } \\
\text { professionals } \\
\text { Wanting facts } \\
\text { about the OHCA } \\
\text { incident }\end{array}$ \\
\hline
\end{tabular}


Participant no. 6: I was very concerned about dying, to die just like that, so horrible and in public and because of my mistakes, that he died because I made mistakes. I was obsessed about this.

Health-educated lay rescuers were more able to feel proud of having provided CPR, even though the OHCA victim did not survive. Their reflection was more directed towards having managed the OHCA incident, without being in a professional setting and without having any medical equipment at hand.

Participant no. 2: From one end to the other, this was a success story, although it did not go well.

Some lay rescuers described influence on work and family life. Unwanted attention after the CPR provision was perceived as stressful by some, while others felt neglected. Some lay rescuers were frightened that unexpected harm would happen to family members.

Participant no. 19: I remember, during work, for a long time, I was always by myself, for many weeks.

\section{Uncertainty}

All the lay rescuers wanted to be informed about the outcome, and several would also appreciate seeing and talking to the OHCA victim. Sometimes, information about the outcome was provided by family, friends or colleagues, while others waited years before they received such knowledge. Health-educated lay rescuers attempted to obtain patient information by using their professional networks. Some lay rescuers put a considerable amount of effort into obtaining information about the outcome. However, the struggle of contacting the hospital, examining newspapers or looking for other signs of survival or death was often futile.

Participant no. 13: I wondered about the outcome. I looked in the newspaper. I checked to see if the flag was flying at half-mast. Did we manage this, or did we not?

The lack of access to information about the outcomes seemed both stressful and unreasonable to several.

Interviewer: What if the patient had actually died?

Participant no. 3: I would rather have known. Because when you eventually find out, you go through an emotional dealing with it, which earlier would probably have prevented some of the mind torment.

Participant no. 4: It doesn't mean that I want to know the name of the patient. That doesn't interest me, but if society wants me to help, they can't cut me off with banal statements about the duty of confidentiality.

Several lay rescuers linked the provided CPR to the outcome of the cardiac arrest victim, causing profound feelings of relief or guilt, depending on whether the victim had a good neurological outcome or not. In cases with poor outcomes, a range of emotions from acceptance to profound sadness was reported. Uncertainty about the outcome seemed to be difficult to deal with.

Participant no. 14: I think about it all the time. I check my mobile phone and wonder when they will call, but they never do.

Participant no. 7: It was an incredible relief when the flowers arrived. It was proof that he was alive and was doing all right.

\section{Coping strategies}

By performing everyday activities, some lay rescuers felt that a kind of normality was brought back in life. Although some lay rescuers wanted to avoid attention after the OHCA incident, they all repeatedly talked about the experience with family and friends. Some lay rescuers were particular about who they wanted to confide in, while others spoke to whoever wanted to listen.

Participant no. 12: I spoke a lot about this incident to everybody I met. That was my way of doing it.

Four of the lay rescuers needed professional counselling to process the OHCA experience, while others contacted health professionals in their network. A few lay rescuers described deep sorrow, even several years after the incident.

Sometimes the EMS personnel provided some kind of feedback at the scene. Except for most of the health-educated lay rescuers, the need for acknowledgement and assurance regarding the adequacy of the CPR provision was reported by all. Most wanted a professional, but optional, follow-up from healthcare professionals to talk about the OHCA incident. They emphasised that they did not want any admiration but clear facts about the OHCA incident and a reassurance that there was nothing else they could have done that would have improved the outcome.

Participant no. 5: It's about acknowledgement. It's about motivation. It's about being trained to save lives, and when we do, nobody cares.

\section{DISCUSSION}

This is one of the very few studies to explore the reactions and coping strategies of lay rescuers following CPR provision for OHCA victims. We used a qualitative research approach and went from coded meaning units to subcategories, further to the categories: concern, uncertainty and coping strategies. The created theme aims at describing the structure of the experience: ${ }^{17}$ emotional and social challenges and the struggle to cope in life after providing CPR. 
In general, we found the lay rescuers to have profound concern for the cardiac arrest victims. Uncertainty about the outcome led to various efforts to obtain information. Until knowledge was achieved, the lay rescuers often blamed themselves for inflicting severe injury or potential death on the OHCA victim. All lay rescuers talked through the OHCA incident with family and friends, and some talked with professional counsellors. Most lay rescuers would have appreciated follow-up by healthcare professionals.

By providing CPR, lay rescuers attempt to improve outcomes, which can be seen as taking moral responsibility for another human being's life. It is well known that some of the most frequently reported barriers to performing CPR are concerns about incorrect CPR provision and potential harm to the cardiac arrest victim. ${ }^{19} 20$ It is plausible that these barriers, even if they are overcome, are strongly connected to the sense of responsibility for another human being's death. Thus, the feelings of guilt reported in this study are comprehensible.

The lay rescuers established a causal relationship between the CPR provided and the outcome and felt guilty when the effort failed. Coping in traumatic incidents has been shown to mitigate stress reactions. ${ }^{21}$ The feeling of coping is closely related to the feeling of having achieved goals. ${ }^{22}$ By regarding survival as the goal, the lay rescuers are at risk for not succeeding, because other influencing factors outside their control contribute to outcome, such as shockable or nonshockable rhythm, witnessed or unwitnessed arrest, EMS response time and age. ${ }^{2}{ }^{4}$ Conversely, the health-educated lay rescuers in our study seemed to focus more on how they had managed the CPR rather than the outcome of the OHCA victim, which was within their control and thus less dependent on influencing factors. Another explanation to the feeling of guilt in lay rescuers may be the exaggerated positive impact of CPR on OHCA outcome represented by the mass media or stakeholders. ${ }^{23} 24$

The emotional and social challenges reported in this study, such as reduced work capacity, weight loss, flashbacks and nightmares, were considerable. These findings are supported by Genest $e t a l^{10}$, who reported that an unsuccessful CPR attempt may lead to persistent adverse consequences. Zijlstra et at did not find significant adverse effects for lay rescuers after providing CPR. However, all the interviewees in that study were connected with an OHCA text message alerting system. In addition, $42 \%$ of lay rescuers were off-duty professional rescuers. This means that the interviewees were mentally prepared for providing CPR to OHCA victims; the results may therefore not be applicable to the general population. Health-educated lay rescuers probably know that other circumstances than the quality of CPR also determine outcomes.

Even when the return of spontaneous circulation was achieved, some of the lay rescuers in this study reported major concerns while the cardiac arrest victim was in hospital care. They did not calm down until they were sure of the victim's survival with a favourable neurological outcome. Using phrases such as 'emotional roller coaster' and 'mind torment', it seemed as though several lay rescuers had experienced challenges in everyday life depending on the cardiac arrest victim's outcome. Thus, information about favourable outcomes was received with great relief, while being in ignorance sometimes generated despair. Acknowledging that CPR provision is challenging and can have consequences, ${ }^{10}$ information about patient outcome may be beneficial to lay rescuers, but raises ethical and legal issues that must be addressed. Before a legislative approach is adopted, this issue should be explored further. Also, considering the emotional cost to lay rescuers providing CPR, the importance of outcome information should not be neglected, but rather carefully facilitated by healthcare workers within legal restrictions. However, if information about positive patient outcomes is essential for processing OHCA incidents in a beneficial way, lay rescuers are highly vulnerable because most OHCA victims do die. ${ }^{4}$ Both a lack of debriefing and fatal patient outcomes are considered to be independent factors associated with a negative OHCA experience, ${ }^{13}$ while debriefing is shown to positively influence the ability to cope with emotional reactions after CPR provision. ${ }^{11}$ Debriefing can stimulate reflection and be valuable, even without involving information about patient outcomes. ${ }^{11}$

The European Resuscitation Council emphasises the importance of bystanders in the latest CPR guidelines. ${ }^{25}$ Thus, lay people are urged to take responsibility for up to three of the four links in the chain of survival in OHCA incidents. ${ }^{26}$ It is encouraging that the number of bystanders who provide CPR is increasing. ${ }^{5}{ }^{6}$ Still, we should acknowledge that lay rescuers are not a homogeneous population. They differ in their preparedness and vulnerability, and the coincidental OHCA factors vary as well. We may have underestimated the negative impact of providing CPR, perhaps because of the great value of saving lives.

This study has identified communication with family and friends as an important coping strategy for processing OHCA incidents, as are attempts to acquire information about the patient's outcome and the need for acknowledgement of the CPR attempt. All humans inevitably experience emotional challenges that they must face and process. Lay rescuers' reactions might reflect both how they cope with providing CPR and a reaction to the experience of witnessing a loved one suffer a cardiac arrest or die. However, public campaigns to save lives by providing CPR affect moral obligations in human beings. Our results show that such obligations can lead to concerns and adverse reactions. Until now, support and counselling have been directed more towards the patient and family. ${ }^{27}$ Being a CPR provider does not necessarily imply the need for professional treatment, but we believe that some sort of an organised follow-up may mitigate concerns, reduce 
uncertainty towards the CPR provided and promote coping strategies in lay rescuers. Also, a follow-up should entail mutual trust between healthcare systems and community citizens. Further studies should identify the extent of the adverse reactions after performing CPR.

\section{LIMITATIONS}

In most of the resuscitations initiated by the participants interviewed in this study, the cardiac arrest victims survived. This does not reflect the survival rate in our area and may have biased the results.

The large variation in time from CPR intervention to interview is a weakness in this study. To some participants more than others, time may have influenced the processing of the OHCA incident and affected the results. However, considering that most of the lay rescuers in this study were interviewed long after the OHCA incident, and the high rate of survival in this study, we expected less emotional reactions after providing CPR. This may indicate that CPR provision with both favourable and unfavourable outcomes causes emotional strain among lay rescuers. The participants volunteered to meet and discuss the OHCA incident up to 13 years after the occurrence and this could suggest that they were still in need of clarification. The selection method for inclusion of participants may have identified a sample of lay rescuers with more severe reactions than shown in other similar studies.

We also experienced a huge challenge in attempting to include CPR providers in the study, especially those who provided CPR to OHCA victims who did not survive. An avoidance of reminders of the OHCA incident could be a reason, which means that in an unselected population, the impact of providing CPR could be even more severe. Future studies should explore the relationship between patient outcome and lay rescuer reactions.

To ensure a diversity of participants, we used various techniques to recruit lay rescuers, which may seem of little consistency. However, to be responsive to real-world conditions, an adaptable sampling strategy was followed. ${ }^{16}$ Our inclusion strategies resulted in various lay rescuers regarding gender, age and the relationship to the cardiac arrest victim, which we regard as a strength by allowing a diversity of perspectives on CPR provision.

We did not use any validated instruments for measuring adverse reactions. Thus, we have avoided any discussion regarding pathological versus normal reactions after experiencing OHCA. This also means that the assessment of the experiences reported by the lay rescuers was left to the authors' discretion.

The researchers of this study have previously conducted a study concerning lay rescuers regarding risk perception in OHCA incidents. The answers from the study may have influenced the researchers preunderstanding in the current study.

\section{CONCLUSIONS AND IMPLICATIONS}

Reactions after providing CPR to OHCA victims may cause serious and persistent concerns in lay rescuers. Non-health-educated lay rescuers seem to establish a causal relationship between the provided CPR and outcome, leading to deep concerns regarding whether their CPR provision led to severe injury or death, and without assessing other factors contributing to patient outcome. Experiencing a positive patient outcome and being a health-educated lay rescuer seem to mitigate concerns. Common coping strategies in lay rescuers were directed towards reducing uncertainty about patient outcome and obtaining assurance regarding their own CPR quality. An organised follow-up may mitigate concerns and adverse reactions in lay rescuers. Further studies should explore the prevalence of concerns and adverse reactions in lay rescuers.

\section{Author affiliations}

${ }^{1}$ Department of Anaesthesiology and Intensive Care, Stavanger University Hospital, Stavanger, Norway

${ }^{2}$ Department of Research and Development, Norwegian Air Ambulance

Foundation, Drøbak, Norway

${ }^{3}$ Department of Clinical Medicine, University of Bergen, Bergen, Norway

${ }^{4}$ Department of Research, Stavanger University Hospital, Stavanger, Norway

${ }^{5}$ Stord/Haugesund University College, Haugesund, Norway

${ }^{6}$ Network for Medical Sciences, University of Stavanger, Stavanger, Norway

Acknowledgements All the authors would like to thank the lay rescuers for participating in this study. They also thank the Stavanger University Hospital Ambulance Services for the distribution of flyers concerning the study, as well as Margot Viste, who transcribed the interviews. They are grateful to Kristine Rørtveit for providing valuable comments on the manuscript.

Contributors WTM contributed in the conception, design, analysis, data interpretation and manuscript writing. CAB involved in the conception, design, analysis, data interpretation and manuscript writing. GSB involved in data interpretation and manuscript writing. ES involved in the conception, design, analysis, data interpretation and manuscript writing.

Funding This project was supported, in part, by The Norwegian Air Ambulance Foundation, Department of Research and Development.

\section{Competing interests None declared.}

Ethics approval The study was approved by the Institutional Review Board at Stavanger Hospital Trust, Norway.

Provenance and peer review Not commissioned; externally peer reviewed.

Data sharing statement The coding schedule and coded segments from the data set are in Norwegian text format and available from wenche.torunn. mathiesen@sus.no. Consent was not obtained from participants for data sharing, but data are anonymised and risk of person identification is low.

Open Access This is an Open Access article distributed in accordance with the Creative Commons Attribution Non Commercial (CC BY-NC 4.0) license, which permits others to distribute, remix, adapt, build upon this work noncommercially, and license their derivative works on different terms, provided the original work is properly cited and the use is non-commercial. See: http:// creativecommons.org/licenses/by-nc/4.0/

\section{REFERENCES}

1. Atwood C, Eisenberg MS, Herlitz J, et al. Incidence of EMS-treated out-of-hospital cardiac arrest in Europe. Resuscitation 2005;67:75-80.

2. Sasson C, Rogers MA, Dahl J, et al. Predictors of survival from out-of-hospital cardiac arrest: a systematic review and meta-analysis. Circ Cardiovasc Qual Outcome 2010;3:63-81. 
3. Ahn KO, Shin SD, Suh GJ, et al. Epidemiology and outcomes from non-traumatic out-of-hospital cardiac arrest in Korea: A nationwide observational study. Resuscitation 2010;81:974-81.

4. Lindner TW, Søreide E, Nilsen OB, et al. Good outcome in every fourth resuscitation attempt is achievable-an Utstein template report from the Stavanger region. Resuscitation 2011;82:1508-13.

5. Fothergill RT, Watson LR, Chamberlain D, et al. Increases in survival from out-of-hospital cardiac arrest: a five year study. Resuscitation 2013;84:1089-92.

6. Wissenberg M, Lippert FK, Folke F, et al. Association of national initiatives to improve cardiac arrest management with rates of bystander intervention and patient survival after out-of-hospital cardiac arrest. JAMA 2013;310:1377-84.

7. Malhotra A, Rakhit R. Improving the UK's performance on survival after cardiac arrest. BMJ 2013;347: 44800 .

8. Ro YS, Shin SD, Kitamura T, et al. Temporal trends in out-of-hospital cardiac arrest survival outcomes between two metropolitan communities: Seoul-Osaka resuscitation study. BMJ Open 2015;5:2015-007626.

9. Zijlstra JA, Beesems SG, De Haan RJ, et al. Psychological impact on dispatched local lay rescuers performing bystander cardiopulmonary resuscitation. Resuscitation 2015;92:115-21.

10. Genest M, Levine J, Ramsden V, et al. The impact of providing help: Emergency workers and cardiopulmonary resuscitation attempts. J Trauma Stress 1990;3:305-13.

11. Møller TP, Hansen CM, Fjordholt M, et al. Debriefing bystanders of out-of-hospital cardiac arrest is valuable. Resuscitation 2014;85:1504-11.

12. Axelsson A, Herlitz J, Fridlund B. How bystanders perceive their cardiopulmonary resuscitation intervention; a qualitative study. Resuscitation 2000;47:71-81.

13. Axelsson A, Herlitz J, Karlsson T, et al. Factors surrounding cardiopulmonary resuscitation influencing bystanders' psychological reactions. Resuscitation 1998;37:13-20.

14. Malterud K. The art and science of clinical knowledge: evidence beyond measures and numbers. Lancet 2001;358:397-400.

15. Marshall MN. Sampling for qualitative research. Fam Pract 1996;13:522-6.
16. Coyne IT. Sampling in qualitative research. Purposeful and theoretical sampling; merging or clear boundaries? J Adv Nurs 1997;26:623-30.

17. Graneheim UH, Lundman B. Qualitative content analysis in nursing research: concepts, procedures and measures to achieve trustworthiness. Nurse Educ Today 2004;24:105-12.

18. Tong A, Sainsbury $P$, Craig J. Consolidated criteria for reporting qualitative research (COREQ): a 32-item checklist for interviews and focus groups. Int J Qual Health Care 2007;19:349-57.

19. Savastano S, Vanni V. Cardiopulmonary resuscitation in real life: the most frequent fears of lay rescuers. Resuscitation 2011;82:568-71.

20. Aaberg AM, Larsen CE, Rasmussen BS, et al. Basic life suppor knowledge, self-reported skills and fears in Danish high school students and effect of a single 45-min training session run by junior doctors; a prospective cohort study. Scand J Trauma Resusc Emerg Med 2014;22:24.

21. Johnsen BH, Eid J, Løvstad T, et al. Posttraumatic stress symptoms in nonexposed, victims, and spontaneous rescuers after an avalanche. J Trauma Stress 1997;10:133-40.

22. Manger T, Nordahl T, Hansen O. Motivasjon og mestring. Oslo: Gyldendal Akademisk, 2012.

23. Diem SJ, Lantos JD, Tulsky JA. Cardiopulmonary resuscitation on television. Miracles and misinformation. $N$ Engl $\mathrm{J}$ Med 1996;334:1578-82.

24. ERC. Your hands can save more lives, 04.11.2015.

25. Perkins GD, Handley AJ, Koster RW, et al. European Resuscitation Council Guidelines for Resuscitation 2015: section 2. Adult basic life support and automated external defibrillation. Resuscitation 2015;95:81-99.

26. Cummins RO, Ornato JP, Thies $\mathrm{WH}$, et al. Improving survival from sudden cardiac arrest: the "chain of survival" concept. A statement for health professionals from the Advanced Cardiac Life Support Subcommittee and the Emergency Cardiac Care Committee, American Heart Association. Circulation 1991;83: 1832-47.

27. Nerla R, Webb I, MacCarthy P. Out-of-hospital cardiac arrest contemporary management and future perspectives. Heart 2015;101:1505-16. 